\title{
Opportunistic Infections and Associated Factors among HIV/AIDS Patients taking Ante-Retroviral Therapy at Selected Hospitals in Sidama Zone, Southern Ethiopia: A facility-based cross-sectional study
}

Demelash Wachamo ( $\nabla$ demmenew1@gmail.com )

Hawassa College of Health Science

Fisseha Bonja

Hawassa University College of Medicine and Health Sciences

Research article

Keywords: Opportunistic infection, HIV/AIDS, WHO clinical stage, Hawassa, Ethiopia

Posted Date: November 12th, 2019

DOI: https://doi.org/10.21203/rs.2.17125/v1

License: (c) (1) This work is licensed under a Creative Commons Attribution 4.0 International License.

Read Full License 


\section{Abstract}

Background Opportunistic infections are late complications of HIV infection is the depletion of the immune system. It is a major public health problem and high morbidity AIDS patients die of AIDS-related infections in developing countries like Ethiopia. Identification of opportunistic infections (Ols) is important to develop a specific intervention. Therefore, this study aimed to assess the burden and associated factors of opportunistic infections.

Method A facility-based cross-sectional study was conducted on 420 randomly selected HIV/AIDS patients taking anti-retroviral therapy. Data was collected from selected hospitals in Sidama Zone based on population proportion to size. Data was collected by a pre-tested questionnaire and a pre-tested checklist from the medical records of patients. Data entry and analyzed for descriptive and logistic regression models by SPSS v.23. The result declared as statistically significant at $p<0.05$.

Result The magnitude of opportunistic infections was $39.6 \%$. Major identified Ols was oral candidacies $23.2 \%$, recurrent bacterial pneumonia $21.5 \%$, Herpes zoster $6.3 \%$, and Pulmonary Tuberculosis $6.0 \%$.The magnitude of opportunistic associated with; older age [AOR=2.69, 95\% Cl: 1.33-5.43], No formal education [AOR=3.12, 95\% Cl: 1.06-9.25], Low monthly income [AOR=2.27, 95\%Cl:1.35-3.83], initial CD4 count less than 200 cells/mm3 [AOR=1.91, 95\% Cl:1.05-3.46), WHO clinical stage II [AOR=2.43, 95\% Cl:1.34-4.42] and stage III and IV [AOR=4.27, 95\% Cl: 2.12-8.59], had no extra medicine additional to ART (prophylaxis) had [AOR= 5.91, 95\% Cl: 3.31-10.56], who interrupt ART medicines [AOR=2.03, 95\% Cl: 1.09 $3.80]$ and Khat chewing [AOR $=5.48,95 \% \mathrm{Cl}$ : 2.32-12.96] when compared to their counterparts.

Conclusions The overall magnitude of opportunistic infections was high when compared with other studies. Health officials and clinicians need to give attention on the strengthening of the provision if ART with prophylaxis on early-stage and adhrerence, implementation of the TB/HIV collaboration activity, and early initiation of ART to reduce opportunistic infections.

\section{Background}

Human immune virus (HIV/ADIS), with which 36.7 million people were living and 2.1 million infected at the end of 2016, has been major health problem throughout the world [1]. Around 36.7 million people worldwide are currently living with HIV, of which $52 \%$ reside in sub-Saharan Africa (SSA) [2]. It affected 1 in every 25 Adults (4.4\%) is living with the deadly virus, account for nearly $70 \%$ of the global burden of HIV $[3,4]$. Although the natural history of HIV inclines to be similar, the patterns of Ols that mainly presented with different clinical manifestation regions to region $[5,6]$. CDC estimates that in $2015,15 \%$ of the people with HIV in the United States were unaware or asymptomatic of their infections $[1,7]$. The commonly reported opportunistic diseases in sub-Saharan Africa among HIV patients are Candidasis, Pneumocystis carinii pneumonia (PCP), disseminated Mycobacterium avium complex (MAC) infection, Cryptococcus, kaposi sarcoma, herpes zoster, and tuberculosis $[8,9]$. 
The developing countries more suffer from bacterial and protozoal infections due to lack of resource [8, 10], HIV diagnosis, sub-optimal HAART use, poor adherence, dug resistance, poverty, poor nutrition, and high exposure to infectious agents [11]. The opportunistic infections may favour HIV replication and higher viral loads that leads to lower the quality of life of HIV infected persons, reduces patients' response to ART, increases stigma and limits one's ability to work, high medical care costs, and death $[12,13]$.

In Ethiopia, the adult HIV prevalence of Ethiopia was estimated to be $1.1 \%$ in 2015, and second leading cause of death [14]. More than $90 \%$ of HIV/AIDS deaths are attributable to opportunistic infections and malignancies [8]. Even though nationally representative and comprehensive data regarding the magnitude of opportunistic infections lacks in Ethiopia, some regional studies has shown the prevalence ranging from $19.7 \%$ to $48 \%[13,15]$. The prevalence of Ols among HIV patients on ART is still high namely; oral candidiasis $11.8 \%$, followed by chronic diarrhea, $9.9 \%$ and tuberculosis $9.7 \%$ at in DebreMarkos referral hospital in Ethiopian [16]. Which associated with age, WHO stages of III and IV, chew khat, ART adherence, low level of hemoglobin, and recent weight [16]. Hence, it is very important to see the magnitude of opportunistic infections and its determinant factors to to reduce the burden. This is important for researchers, clinicians, and health planners.

\section{Methods}

The source population was all HIV/AIDS patients who visited ART clinic of the selected three hospital in Sidama zone, southern Ethiopia. While all randomly selected adults from selected hospitals within Feburuary, 01 up to May, 01, 2019 preceding the study. The study was conducted on 420 calculated by a single population proportion formula by taking previously conducted prevalence of opportunistic infections in DebreMarkos Referral Hospital, Northwest Ethiopia [16] and 10\% possible non-response rate. The study participants sampled according to their randomly arrivival of selected hospitals. Data was collected by face to face interview by using pre-tested questionnaire; a pre-tested checklist done to collect information regarding Ols and patients' clinical records were reviewed. The age of 18 years or older adults was included. All adults who, are unable to be interviewed, were excluded from the study.

\section{Data collection method and processing}

A pre-tested structured questionnaire was utilized to collect socio-demographic characteristics, clinical information and other risk factors. The questionnaires were pretested and validated before two weeks in the study time in Dore Bafana primary hospital on $5 \%$ of HIV positive patients who attend ART clinic which was outside of the study area and necessary modifications were done based on the findings. Data collectors were five clinical nurses supervised by one BSC nurse supervisor and investigators. Training and practical demonstrations on interview techniques and document extraction procedures based on check list were given to data collectors for two consecutive days assessed for competency.

\section{Quality control and data analysis}


Data collectors were trained and the questioners were pretested before the study time. After data collection process, the data were checked for completeness and any incomplete or misfiled questionnaires filed again.

Data entry, cleaning, and analysis were done by SPSS V. 23. All factors with a p-value $<0.2$ in the bivariate logistic regression analysis were a candidate to the multivariable model to control confounding effects.

The Hosmer -Lemeshow goodness-of-fit statistic was used to assess whether the necessary assumptions for the application of multiple logistic regression are fulfilled. Odds ratios (OR) with $95 \%$ confidence intervals $(\mathrm{Cl})$ were calculated. Finally, p-value $<0.05$ declared a significant association.

Ethical clearance was obtained from Hawassa university college of medicine and health sciences ethical review committee, support letter was also requested from the Sidama zone health bureau. All participants informed well about purpose, risk and benefit, and confidentiality. Participation was fully voluntary and written informed consent (verbal consent for who cannot read and write respondent) was obtained from each participant. The patients' medical records were reviewed anonymously, and all information obtained from medical records was kept confidential.

\section{Terms and definitions}

Opportunistic infection-If the study participant diagnosed atleast were one or more opportunistic infections; any infections of bacteria, viruses, fungi, Parasitic or protozoa or multiple infections reported on their medical record [7].

Adverse effect-an unwanted effect caused by the administration of drugs. On set may be sudden or developed over time.

Highly active antiretroviral therapy (HAART)-the name given to treatment regimens meant to aggressively suppress viral replication and progress of HIV disease the usual HAART regimen combines three or more different drugs.

- Cigarette smokers: who had used cigarette smokers form of tobacco in the last 30 days [17].

\section{Results}

A total of 414 participants (aged 18-55 years, with the mean $( \pm S D)$ age of $30.69( \pm 7.350)$ were interviewed yielding a response rate of $98.57 \%$. More than half of the studied participants $234(56.5 \%)$ were female and $171(41.3 \%)$ in the age category of 25 - 34 years old. The majority of $259(62.6 \%)$ were married and 264(63.8\%) were live with their family. Regarding ot educational stus, 25 (6.0\%) have no formal education, $102(24.6 \%)$ had a primary school, and $287(69.3 \%)$ had high school and above education. The working status of the participants 278 (67.1\%) were actively working. The monthly income of the households, 223 (53.9\%) earned between 300 - 1920 ETB, and 191 (46.1\%) earned more than 1920 ETB (Table 1). 


\section{Environmental and Behavioral related characteristics}

The majority of 273 (65.9\%) were live in cemented floor house. Most of 401 (96.9\%) had latrine, among this $395(95.4 \%)$ were shared with their family and neighbors. More than half of $287(69.8 \%)$ used Garbage can or sac to disposer refuse. Main source of drinking water was 398 (96.1\%) pipe water. Regarding to behavioural related factors, $27(6.5 \%)$ were used any tobacco products, among this 14 (3.4\%) were current cigarette smokers. The prevalence of Khat chewing was 48 (11.6\%). Regarding to alcohol consumption, 71 (17.1\%) were ever drunk alcohol, 63 (15.2\%) were drinking alcohol in last 30 days (Table 2).

\section{Health care system and Clinical Setting related factors}

Out of the respondents, 263 (63.5\%) were had doubts on ARV and health care provider. Majority of 376 (90.8\%) were know the importance of adherence on ART and 352 (85.0\%) were believe it improve life. Majority of participants agree, 408 (98.6) were on prevent Ols and AIDS. While, 324 (78.3\%) were disclosed HIV status to family and relatives (S1).

\section{Patient health condition related factors}

More than half of the participants report 249 (60.1\%) were feel nothing during taking ART drugs transparently. Majority of, $333(80.4 \%)$ were ART drugs is comfortable daily activity with for years mean ( \pm SD), $4.8( \pm 3.33)$ on HAART. While, $83(20.0 \%)$ were experience side effect on ART drugs and $202(48.8 \%)$ were took extra drugs additional to ART drugs (S1). Nearly half of, 195 (47.1\%) were on WHO clinical stage I, while $122(29.5 \%), 63(15.2 \%)$, and 34 (8.2\%) were on WHO clinical stage II - IV, respectively (Fig. 1).

\section{Maginitude of Opportunistic Infections}

The overall magnitude of opportunistic infections was 39.6\%, [95\% Cl: 35.0 - 44.4] were found to be infected by one or more opportunistic infections among HIV/AIDS Patients taking ART at Selected Hospitals in Sidama Zone, Southern Ethiopia. Major identified opportunistic infections were oral candidacies 96 (23.2\%), recurrent bacterial pneumonia 89 (21.5\%), Herpes zoster 26 (6.3\%), Pulmonary Tuberculosis 25 (6.0\%), Extra pulmonary TB. 24 (5.8\%), and Crypto-coca meningitis 9 (2.2\%) (Fig. 2).

\section{Associated Factors for Opportunistic Infections}

In the multivariate analysis age of respondent, household monthly income, initial CD 4 count, WHO clinical staging, education, had no extra medicine additional to ART (prophylaxis), taking ART medicines properly, and Khat chewing were remains as determinant of opportunistic infections. This study result shows that 
the advancing in the age had about 2.7 times more exposed to develop Ols [AOR $=2.69,95 \% \mathrm{Cl}$ : $1.33-$ 5.43] as compared with younger age. No formal education had [AOR $=3.12,95 \% \mathrm{Cl}: 1.06-9.25]$, Low household monthly income had [AOR $=2.27,95 \% \mathrm{Cl}$ : $1.35-3.83]$, had more exposed to Ols as to their counterparts. Initial CD4 count less than $200 \mathrm{cells} / \mathrm{mm}^{3}$ had [AOR $\left.=1.91,95 \% \mathrm{Cl}: 1.05-3.46\right)$, WHO clinical stage II [AOR $=2.43,95 \% \mathrm{Cl}: 1.34-4.42]$ and stage III and IV [AOR $=4.27,95 \% \mathrm{Cl}: 2.12-8.59]$, had high odds of to develop Ols when compared with WHO clinical stage I participants. The study prticipants who had no extra medicine additional to ART (prophylaxis) [AOR $=5.91,95 \% \mathrm{Cl}: 3.31-10.56]$, interrupt ART medicines had [AOR $=2.03,95 \% \mathrm{Cl}: 1.09,3.80]$ and Khat chewing $[\mathrm{AOR}=5.48,95 \% \mathrm{Cl}$ : 2.32-12.96] were more exposed to Ols when compared to their counterparts (Table 3 ).

\section{Discussion}

This facility-based cross-sectional study revealed that, the maginitude of opportunistic infections was $39.6 \%$, [95\% Cl: 35.0 - 44.4] were found to be infected by one or more opportunistic infections among HIV/AIDS Patients taking ART at Selected Hospitals in Sidama Zone, Southern Ethiopia. Major identified opportunistic infections were Oral candidacies $23.2 \%$, recurrent bacterial pneumonia $21.5 \%$, Herpes zoster $6.3 \%$, and Pulmonary Tuberculosis $6.0 \%$. This study result was consistent with the study findings in Wolaita Zone, Southern Ethiopia 45.3\% [8] and Uganda 43\% [9]. This result higher when compared eastern Ethiopia 20.2\% had any form of tuberculosis, oral candidiasis, herpes zoster [13], 22.4\% Nigeria [18], 19.7\% Northern Ethiopia [19]. While, it was slightly lower when compared with 61.7\% Nigeria [18], 47.6\% Taiwan [20], and 48\% eastern Ethiopia [13]. The discrepancy might be due to difference in geographical areas of study participants, high exposure to infectious agents, social-economic status, drug resistance, immunity and nutrition, may affect the magnitude of Ols.

This study result revealed that the advancing in the age was more exposes to Ols as compared with younger age. Similar with the United States [21], and Northwest Ethiopia [22]. The possible reason may be, when they grow older the patients immune get decreased due to increased number of viral load and other factors predispose for Ols. Inaddition to that the study participants who had no formal education exposes to Ols more when compared with high and above education. This finding was also similar with DebreMarkos Referral Hospital, Northwest Ethiopia [22], and eastern Ethiopia [13]. This may due to lack of health-related information about prevention, early symptoms and health benefits. Low household monthly income was more exposed to Ols as to their counterparts. This finding is consistent with Bangladesh [23], and Lao People's Democratic Republic (PDR) [24]. This might due to house hold income directly related with nutritional status and sanitation status of the individuals.

Initial CD 4 count less than 200 cells/mm3 was more exposed to Ols as compared with higher CD4 count. This study finding agree with eastern Ethiopia [13], and Amhara region, Ethiopia [25]. This might due to low body defense mechanism favoured the Ols. Futhermore, advancing in WHO clinical stage to II, III and IV was more exposes to Ols as compared with stage I. This study finding in line with Wolaita Zone, Southern Ethiopia [8], eastern Ethiopia [13] and Dessie hospital ART clinic, Northeast Ethiopia [26]. This 
might due to Ols are caused when patient become late on WHO clinical staging which determine to develop AIDS.

The study prticipants who interrupt ART medicines and who had no extra medicine additional to ART (prophylaxis) had high odds of to develop Ols. This study finding consistent with eastern Ethiopia [13], and Dessie hospital ART clinic, Northeast Ethiopia [26]. This might due to Ols could be prevented by using extra drugs additional to ART drugs or prophylaxis.

This study result showed that Khat chewing were more exposed to Ols. Similarly reported in Northwest Ethiopia [22], and eastern Ethiopia [13]. The possible reason may be, chewing Khat cause malnutrition due to poor appitiet and it affect health seeking behavior by temporary relief.

This study result shows there was high prevalence of Ols. This may due to there are endemic intestinal parasite in the area which expose the patient on daily activities or this could be a sign of resistance/ treatment failure that needs to be further investigated. Which related to occurred irrespective of the income status, chewing Khat, interrupt ART medicines and who had no extra medicine additional to ART (prophylaxis), low educational status and due to poor level of health seeking behaviour of the study participants. This study findings recommend for more consideration on different strategies to address early detection for better prevention, evaluation, and management. Future research should explore more by triangulating with qualitative study for factors with Ols to design taregeted interventions.

This study has potential limitations as the study is cross-sectional in design; it neither represents seasonal variation of nutritional outcomes nor establishes causal relationship.

\section{Conclusions}

This study result shows there was high prevalence of opportunistic infection among HIV/AIDS patients taking anti-retroviral therapy. This indicates that the threatening burden of opportunistic infections couldn't be averted by only provision of ante-retroviral therapy. The most common opportunistic infections were of oral candidiasis, herpes zoster and tuberculosis (pulmonary and extra pulmonary). Older age of respondent, household monthly income, initial CD4 count, advancing WHO clinical staging, had no formal education, had no extra medicine additional to ART (prophylaxis), prticipants who interrupt ART medicines, and Khat chewing were found determinant factors for opportunistic infections when compared to their counterparts.

\section{Declarations}

\section{Abbreviations}

ART = Ante-retroviral therapy, CD4 = Cell with CD -4 marker, HAART $=$ Highly active anti-retroviral therapy, Ols = Opportunistic infections, SPSS = Statistical Package for Social Science, STD = Sexually transmitted disease, TB = Tuberculosis, WHO = World Health Organization 


\section{Consent for publication}

Not applicable.

\section{Availability of data and materials}

There is no remaining data and materials, all information is clearly presented in the main manuscript.

\section{Competing interests}

The authors declare that they have no conflict of interests.

\section{Funding}

No funding was obtained.

\section{Authors' contributions}

DW wrote the proposal, participated in data collection, analyzed the data and drafted the paper and manuscript writing. FB approved the proposal with some revisions, participated in data collection, analysis. authors read and approved the final manuscript.

\section{Acknowledgements}

The authors would like to thank Hawassa University, College of Medicine and Health Science for ethical approival. We would like to thanks to Sidama zone health bureau for their cooperation on providing, information and support letter. The authors are also grateful to the all data collectors and study participants for their valuable contribution.

\section{References}

1. UNAIDS. Global AIDS update 2016. Geneva. WHO/UNAIDS. 2016.

2. CampBinford M, Kahana S Y, Altice F L. A Systematic Review of Antiretroviral Adherence Interventions for HIV-Infected People Who Use Drugs. Current HIV/AIDS reports. 2012;9(4):287-312.

3. Csete J, Kamarulzaman A, Kazatchkine M, Altice F, Balicki M, et al. Public health and international drug policy. Lancet (London, England). 2016;387(10026):1427-80.

4. Heestermans T, Browne J L, Aitken S C, Vervoort S C, Klipstein-Grobusch K. Determinants of adherence to antiretroviral therapy among HIV-positive adults in sub-Saharan Africa: a systematic review. BMJ Global Health. 2016;1(4):e000125. 
5. Pantoja T, Opiyo N, Lewin S, Paulsen E, Ciapponi A, et al. Implementation strategies for health systems in low-income countries: an overview of systematic reviews. The Cochrane Database of Systematic Reviews. 2017(9):CD011086.

6. lacob S A, lacob D G, Jugulete G. Improving the Adherence to Antiretroviral Therapy, a Difficult but Essential Task for a Successful HIV Treatment-Clinical Points of View and Practical Considerations. Frontiers in Pharmacology. 2017;8:831.

7. Panel on Opportunistic Infections in Adults and Adolescents with HIV. Guidelines for the prevention and treatment of opportunistic infections in adults and adolescents with HIV: recommendations from the Centers for Disease Control and Prevention, the National Institutes of Health, and the HIV Medicine Association of the Infectious Diseases Society of America.: AIDSinfo; 2019. 1-5]. Available from: http://aidsinfo.nih.gov/contentfiles/lvguidelines/adult_oi.pdf.

8. Alemayehu M, Yisehak Y, Alaro W, Alemayehu B. Opportunistic Infections among HIV/AIDS Patients taking Ante-Retroviral Therapy at Tertiary Care Hospital in Wolaita Zone, Southern Ethiopia. J AIDS Clin Res 2017;8:665.

9. Rubaihayo J, Tumwesigye N M, Konde-Lule J. Trends in prevalence of selected opportunistic infections associated with HIV/AIDS in Uganda. BMC Infectious Diseases. 2015;15:187.

10. Oral abstracts of the 21 st International AIDS Conference. Journal of the International AIDS Society. 2017;20(Suppl 5):22253.

11. Rubaihayo J, Tumwesigye N M, Konde-Lule J, Wamani H, Nakku-Joloba E, et al. Frequency and distribution patterns of opportunistic infections associated with HIV/AIDS in Uganda. BMC Research Notes. 2016;9:501.

12. Jaillette E, Girault C, Brunin G, Zerimech F, Chiche A, et al. French Intensive Care Society, International congress - Réanimation 2016. Annals of Intensive Care. 2016;6(Suppl 1):50.

13. Mitiku $\mathrm{H}$, Weldegebreal $F$, Teklemariam Z. Magnitude of opportunistic infections and associated factors in HIV-infected adults on antiretroviral therapy in eastern Ethiopia. HIV/AIDS (Auckland, NZ). 2015;7:137-44.

14. WHO. HIV/AIDS facts sheet. Geneva. WHO. 2015.

15. Kindie E, Alamrew Anteneh Z, Worku E. Time to development of adverse drug reactions and associated factors among adult HIV positive patients on antiretroviral treatment in Bahir Dar City, Northwest Ethiopia. PLOS ONE. 2017;12(12):e0189322.

16. Moges NA, Kassa GM. Prevalence of opportunistic infections and associated factors among HIV positive patients taking antiretroviral therapy in Debremarkos referral hospital, Northwest Ethiopia. $J$ AIDS Clin Res 2014;5:301.

17. World Health Organization W. Chronic diseases and health promotion. STEP wise approach to chronic disease risk factor surveillance (STEPS). . Geneva:World Health Organization. 2010.

18. Iroezindu MO, Ofondu EO, HauslerH, B V. Prevalence and risk factors for opportunistic infections in hiv patients receiving antiretroviral therapy in a resource-limited setting in Nigeria. . J AIDS Clinic Res 
S. 2013:3: 002.

19. Damtie D, Yismaw G, Woldeyohannes D, Anagaw B. Common opportunistic infections and their CD4 cell correlates among HIV-infected patients attending at antiretroviral therapy clinic of Gondar University Hospital, Northwest Ethiopia. . BMC Res Notes 2013;6:534.

20. Sun HY, Chen MY, Hsieh SM. Changes in the clinical spectrum of opportunistic illnesses in persons with HIV infection in Taiwan in the era of highly active antiretroviral therapy. Jpn J Infect Dis 2006;59:311-6.

21. Mackellar D A, Valleroy L A, Secura G M, Behel S, Bingham T, et al. Unrecognized HIV infection, risk behaviors, and perceptions of risk among young men who have sex with men: opportunities for advancing HIV prevention in the third decade of HIV/AIDS. JAIDS Journal of Acquired Immune Deficiency Syndromes. 2005;38(5):603-14.

22. Moges N, Kassa G. Prevalence of Opportunistic Infections and Associated Factors among HIV Positive Patients taking Anti-Retroviral Therapy in DebreMarkos Referral Hospital, Northwest Ethiopia. Journal of AIDS \& Clinical Research. 2014;05.

23. Peltzer K, Pengpid S. Socioeconomic Factors in Adherence to HIV Therapy in Low- and Middleincome Countries. Journal of Health, Population, and Nutrition. 2013;31(2):150-70.

24. Hansana V, Sanchaisuriya P, Durham J, Sychareun V, Chaleunvong K, et al. Adherence to Antiretroviral Therapy (ART) among People Living With HIV (PLHIV): a cross-sectional survey to measure in Lao PDR. BMC Public Health. 2013;13:617-.

25. Mitku A A, Dessie Z G, Muluneh E K, Workie D L. Prevalence and associated factors of TB/HIV coinfection among HIV Infected patients in Amhara region, Ethiopia. African Health Sciences. 2016;16(2):588-95.

26. Missaye A, Dagnew M, Alemu A, Alemu A. Prevalence of intestinal parasites and associated risk factors among HIV/AIDS patients with pre-ART and on-ART attending Dessie hospital ART clinic, Northeast Ethiopia. AIDS Research and Therapy. 2013;10:7-.

\section{Tables}

Table 1: Socio-demographic characteristics of the study participants among HIV/AIDS Patients taking ART at Selected Hospitals in Sidama Zone, Southern Ethiopia, 2019. 


\begin{tabular}{|c|c|c|}
\hline Category & No. & $(\%)$ \\
\hline \multicolumn{3}{|l|}{ Age of Respondents } \\
\hline $18-24$ years & 89 & $(21.5)$ \\
\hline 25 - 34 years & 171 & $(41.3)$ \\
\hline 35 or above years & 154 & $(37.2)$ \\
\hline \multicolumn{3}{|l|}{ Sex of respondents } \\
\hline Male & 180 & $(43.5)$ \\
\hline Female & 234 & $(56.5)$ \\
\hline \multicolumn{3}{|l|}{ Marital status } \\
\hline Married & 259 & $(62.6)$ \\
\hline Unmarried & 54 & $(13.0)$ \\
\hline Divorced & 50 & $(12.1)$ \\
\hline Separated & 14 & $(3.4)$ \\
\hline Widowed & 37 & $(8.9)$ \\
\hline \multicolumn{3}{|l|}{ Education status } \\
\hline No formal education & 25 & $(6.0)$ \\
\hline Elementary School & 102 & $(24.6)$ \\
\hline High School & 254 & $(61.4)$ \\
\hline Diploma and Above & 33 & $(8.0)$ \\
\hline \multicolumn{3}{|l|}{ Working situation } \\
\hline Working actively & 278 & $(67.1)$ \\
\hline Unemployed & 121 & $(29.2)$ \\
\hline Pensioner & 15 & $(3.6)$ \\
\hline \multicolumn{3}{|l|}{ Live with } \\
\hline My family & 264 & $(63.8)$ \\
\hline Live alone & 77 & $(18.6)$ \\
\hline My parents & 54 & $(13.0)$ \\
\hline Unstable & 16 & $(3.9)$ \\
\hline No answer & & $(0.7)$ \\
\hline \multicolumn{3}{|c|}{ Household income in Ethiopian Birr } \\
\hline $300-1920$ & 223 & $(53.9)$ \\
\hline$>1920$ & 191 & $(46.1)$ \\
\hline
\end{tabular}

NB: Working actively (government, NGO, Private and self employed), Income: based on (HCE, 2016) Exchange rate 1 USD to $29.3673 E T B$

Table 2: Environmental and Behavioral related characteristics among HIV/AIDS Patients taking ART at Selected Hospitals in Sidama Zone, Southern Ethiopia, 2019. 


\begin{tabular}{|c|c|}
\hline Variable Category & No. (\%) \\
\hline \multicolumn{2}{|l|}{ Floor of living house } \\
\hline Mud & 89 (21.5) \\
\hline Cement & $273(65.9)$ \\
\hline Wood & $40(9.7)$ \\
\hline Others & $12(2.9)$ \\
\hline \multicolumn{2}{|l|}{ Latrine available } \\
\hline Yes & 401 (96.9) \\
\hline No & $13(3.1)$ \\
\hline \multicolumn{2}{|l|}{ Ownership of the latrine } \\
\hline Private Owned & $19(4.6)$ \\
\hline Shared with neighbors & $395(95.4)$ \\
\hline \multicolumn{2}{|c|}{ Source of water for drink } \\
\hline Pipe & $398(96.1)$ \\
\hline Others & $12(4.9)$ \\
\hline \multicolumn{2}{|c|}{ Living with domestic animals and pets } \\
\hline Yes & $108(26.1)$ \\
\hline No & 306 (73.9) \\
\hline \multicolumn{2}{|l|}{ Use any tobacco products } \\
\hline Yes & 27 (6.5) \\
\hline No & 387 (93.5) \\
\hline \multicolumn{2}{|c|}{ Smoke cigarettes in last 30 days } \\
\hline Yes & $14(3.4)$ \\
\hline Never & 400 (96.6) \\
\hline \multicolumn{2}{|l|}{ Ever drunk alcohol } \\
\hline Yes & $71(17.1)$ \\
\hline No & 343 (82.9) \\
\hline \multicolumn{2}{|l|}{ Currently drinking } \\
\hline Yes & $63(15.2)$ \\
\hline No & 351 (84.8) \\
\hline \multicolumn{2}{|l|}{ Khat chewing } \\
\hline Yes & 48 (11.6) \\
\hline No & 366 (88.4) \\
\hline
\end{tabular}

Table 3: Bivariable and multivariable logistic regression analysis for opportunistic infections among on ART patients at selected hospitals in Sidama Zone, Southern Ethiopia, 2019. 


\begin{tabular}{|c|c|c|c|c|c|}
\hline & \multicolumn{2}{|c|}{ Opportunistic infection } & \multirow[b]{2}{*}{ COR $(95 \% \mathrm{CI})$} & \multirow[b]{2}{*}{ AOR $(95 \% \mathrm{CI})$} & \multirow[b]{2}{*}{ P-Value } \\
\hline & $\begin{array}{c}\text { Yes } \\
\text { No. (\%) } \\
\end{array}$ & $\begin{array}{c}\text { No } \\
\text { No. }(\%) \\
\end{array}$ & & & \\
\hline \multicolumn{6}{|l|}{ je } \\
\hline $8-24$ years & $20(22.5)$ & $69(77.5)$ & 1 & 1 & \\
\hline 5 - 34 years & $66(38.6)$ & $105(61.4)$ & $2.17(1.21,3.89)$ & $1.28(0.63,2.59)$ & 0.495 \\
\hline 5 or above years & $78(50.6)$ & $76(49.4)$ & $3.54(1.96,6.39)$ & $2.69(1.33,5.43)$ & $0.006^{*}$ \\
\hline \multicolumn{6}{|c|}{ lucation status of respondents } \\
\hline lo formal education & $15(60.0)$ & $10(40.0)$ & $2.76(1.20,6.37)$ & $3.12(1.06,9.25)$ & $0.040^{*}$ \\
\hline lementary School & $48(47.1)$ & $54(52.9)$ & $1.64(1.04,2.59)$ & $1.11(0.62,1.96)$ & 0.733 \\
\hline $\begin{array}{l}\text { igh School and Above } \\
\text { rerage monthly incom }\end{array}$ & $101(35.2)$ & 186 (64.8) & 1 & 1 & \\
\hline 1920 ETB & $107(48.0)$ & $116(52.0)$ & $2.17(1.44,3.26)$ & $2.27(1.35,3.83)$ & $0.002 *$ \\
\hline $\begin{array}{l}920 \text { and above } \\
\text { itial CD4 count }\end{array}$ & $57(29.8)$ & $134(70.2)$ & 1 & 1 & \\
\hline 200 cells $/ \mathrm{mm} 3$ & $26(54.2)$ & $22(45.8)$ & $1.95(1.07,3.58)$ & $1.22(0.53,2.81)$ & 0.643 \\
\hline 200 cells $/ \mathrm{mm} 3$ & $138(37.7)$ & $228(62.3)$ & 1 & 1 & \\
\hline \multicolumn{6}{|l|}{ HO clinical staging } \\
\hline tage I & $39(20.0)$ & $156(80.0)$ & 1 & 1 & \\
\hline tage II & $61(49.2)$ & $63(50.8)$ & $3.87(2.36,6.37)$ & $2.43(1.34,4.42)$ & $0.003 *$ \\
\hline tage III and IV & $64(67.4)$ & $31(32.6)$ & $8.26(4.75,14.37)$ & $4.27(2.12,8.59)$ & $<0.001 *$ \\
\hline \multicolumn{6}{|c|}{ ıke extra medicine additional to ART (prophylaxis) } \\
\hline es & $25(13.8)$ & $156(86.2)$ & 1 & 1 & \\
\hline lo & $139(59.7)$ & $94(40.3)$ & $9.23(5.62,15.16)$ & $5.91(3.31,10.56)$ & $<0.001 *$ \\
\hline \multicolumn{6}{|c|}{ ıking ART medicines properly } \\
\hline es & $115(34.5)$ & $218(65.5)$ & 1 & 1 & \\
\hline lo & $49(60.5)$ & $32(39.5)$ & $2.90(1.76,4.78)$ & $2.03(1.09,3.80)$ & $0.027 *$ \\
\hline \multicolumn{6}{|c|}{ noke cigarettes in last 30 days } \\
\hline lo & $155(38.8)$ & $245(61.3)$ & 1 & 1 & \\
\hline es & $9(64.3)$ & 5 (35.7) & $2.85(0.94,8.65)$ & $1.30(0.26,6.60)$ & 0.752 \\
\hline \multicolumn{6}{|l|}{ rat chewing } \\
\hline ro & $131(36.0)$ & $233(64.0)$ & 1 & 1 & \\
\hline es & $33(66.0)$ & $17(34.0)$ & $3.45(1.85,6.44)$ & $5.48(2.32,12.96)$ & $<0.001 *$ \\
\hline
\end{tabular}

NB: * statistically significant on multivariate analysis p-value (<0.05), COR: crude odds ratio, AOR: adjusted odds ratio, CI: confidence interval, 1: reference.

\section{Figures}




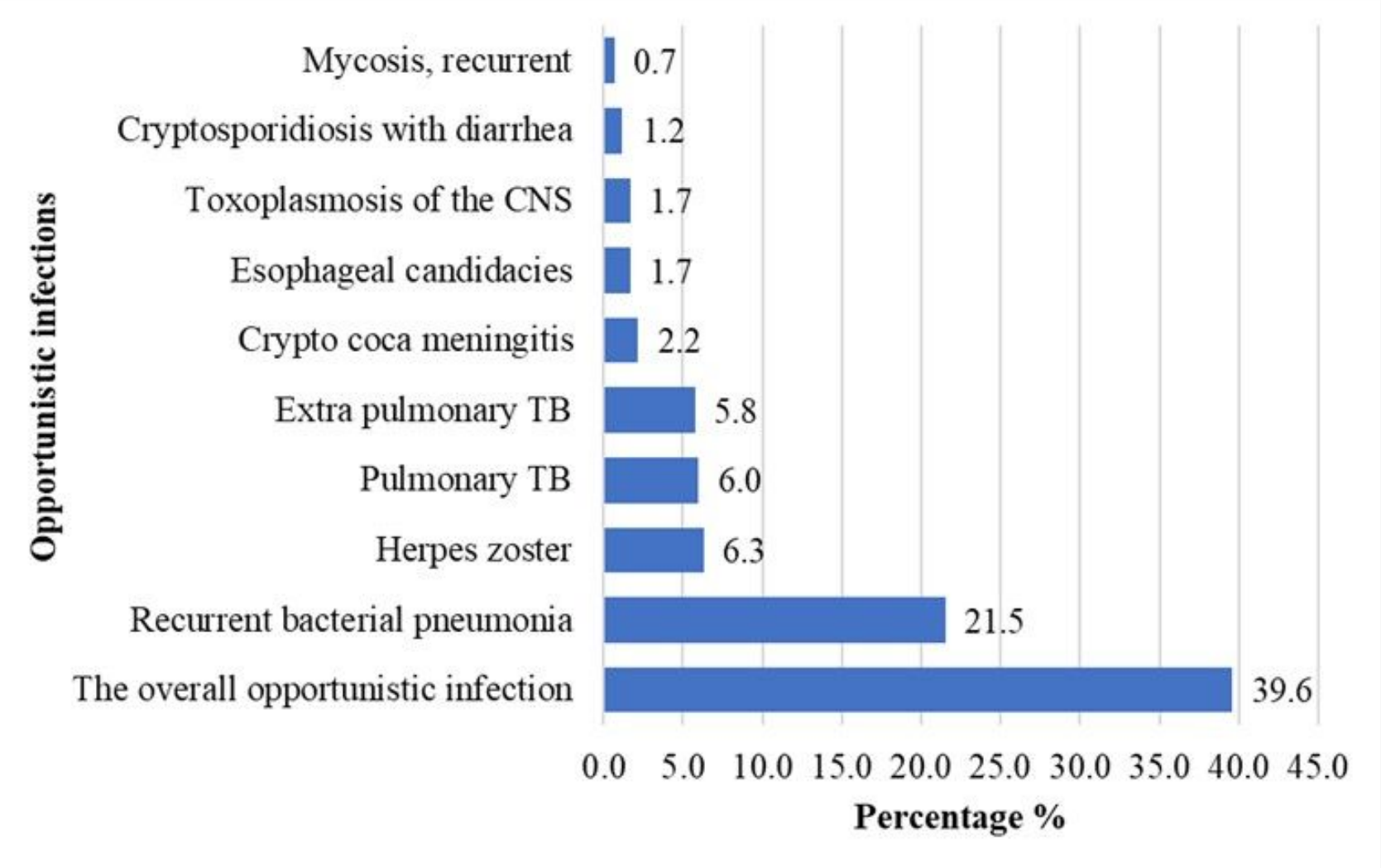

Figure 1

Magnitude of opportunistic infections among HIV/AIDS on ART at Selected Hospitals in Sidama Zone, Southern Ethiopia $2019(n=414)$. 


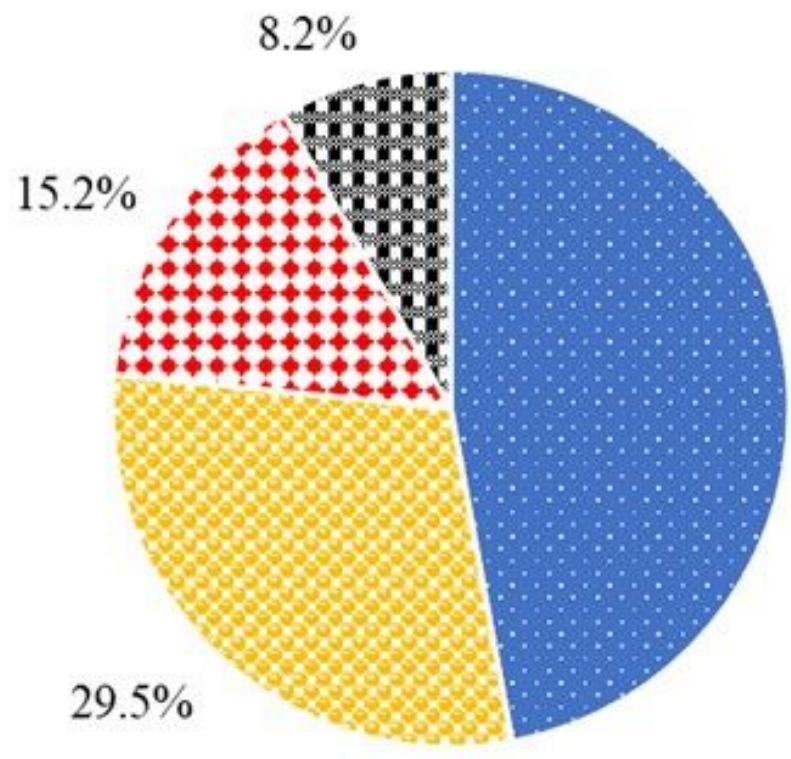

$47.1 \%$

= Stage I

Stage II

: Stage III

Stage IV

Figure 2

WHO clinical staging among HIV/AIDS on ART at Selected Hospitals in Sidama Zone, Southern Ethiopia $2019(n=414)$.

\section{Supplementary Files}

This is a list of supplementary files associated with this preprint. Click to download.

- Supplementarymaterials.rar 